\title{
CONSTRUINDO ALIANÇAS ESTRATÉGICAS PARA A PRODUÇÃO NA SÉTIMA ARTE: UM ESTUDO MULTICASOS EM PRODUTORAS CINEMATOGRÁFICAS BRASILEIRAS
} BUILDING STRATEGIC ALLIANCES
IN PRODUCTION IN THE SEVENTH ART:
A MULTICASE STUDY OF BRAZILIAN FILMS PRODUCERS

Data de submissão: 13-05-2015 Aceite: 29-01-2016

Carlos Alberto Gonçalves ${ }^{1}$

Everton Rodrigues Silva ${ }^{2}$

Daniel Paulino Teixeira Lopes ${ }^{3}$

\section{RESUMO}

O setor cinematográfico carrega a ambiguidade de ser uma atividade industrial e simbólica relevante para a identidade nacional. A despeito de sua significância, há uma lacuna acadêmica sobre o papel das alianças no modelo produtivo brasileiro. Optou-se, diante disso, por entender tal processo através da investigação da estrutura da indústria e da visão baseada em recursos. Este trabalho possui natureza qualitativa, fazendo uso de multicasos e de entrevistas semiestruturadas. Constatou-se que, em função do domínio oligopolista das majors, o setor nacional herdou o padrão americano de divisão de receitas entre os participantes da cadeia produtiva. Entretanto, a estrutura mercadológica dos Estados Unidos é baseada na integração vertical e em uma relação estreita com a televisão. Esses fatos, somados ao abandono do Estado no que diz respeito ao investimento direto na produção, à diminuição do ciclo de vida do filme e ao baixo percentual de projetos que captam recursos via leis de incentivo, asseveraram a competitividade. Percebeu-se que as alianças são um movimento necessário para o funcionamento da cadeia (complementariedade de recursos), mas que há, também, uma relação de dependência das produtoras com os demais elos do sistema de valor, em função da assimetria de poder criada pela estrutura da indústria. É possível afirmar, assim, que complementariedade e dependência andam pari passu.

Palavras-chave: Cinema. Indústria Cinematográfica. Alianças Estratégicas. Produção de Filme. Sétima Arte.

\footnotetext{
1 Possui graduação pela Universidade Federal de Minas Gerais e Fundação Mineira de Cultura - Belo Horizonte, MG. E-mail: carlos@face. ufmg.br

2 Possui graduação pela Universidade Federal de Minas Gerais - Belo Horizonte, MG. E-mail: everton.rsilva@gmail.com

3 Possui graduação em Bacharelado em Administração pela Universidade Federal de Minas Gerais, UFMG, mestrado em Administração pela Universidade Federal de Minas Gerais, UFMG e doutorado em andamento em Administração pela Universidade Federal de Minas Gerais, UFMG. Belo Horizonte. Minas Gerais. Brasil. E-mail: daniel.lopes@globo.com
} 


\begin{abstract}
The movie industry is characterized by the ambiguity of being an industrial activity and a symbolic to the national identity. Despite its relevance, there is a literature gap concerning the role of alliances in the national film production. We sought to understand this process through the lens of the industry structure and the resource-based view. This study was qualitative in nature on the basis of a multiple case study approach and semi-structured interviews. The findings showed that, due to the majors' oligopolistic domain, the national industry inherited the North American pattern for revenue-sharing among participants in the production chain. However, the United States market structure is based in both vertical integration and strong ties between the movie industry and the television industry. Analyzing the Brazilian movie industry, government resignation from investing in production, reduced film lifecycles, and few projects funded privately (via incentive laws), competition between productions is fierce. We found not only that alliances are essential to the functioning of the industry (resource complementarity), but also that producers are strongly dependent to other elements in the movie value system - particularly due to power asymmetries created by the industry structure. Complementarity and dependency go hand in hand.
\end{abstract}

Keywords: Movies. Movie Industry. Strategic Alliances. Film Production. Seventh Art.

\title{
1 INTRODUÇÃO
}

A expansão global dos mercados, a velocidade dos avanços tecnológicos, o desenvolvimento de inovações e o crescente compartilhamento de conhecimentos são aspectos que caracterizam o momento atual de transição econômica e social. Em função dos altos níveis de investimento e risco enfrentados pelas empresas, as alianças estratégicas surgem como uma perspectiva de ação importante no contexto empresarial caracterizado por novas formas de competição (BALESTRIN; VERSCHOORE; REYES JUNIOR, 2010; PELLEGRIN et al., 2007). A esse respeito, Balestrin e Verschoore (2008) mencionam que a nova competição é marcada pela especialização flexível, por um aprimoramento contínuo dos produtos e serviços, pela parceria com fornecedores, clientes e concorrentes - em condições de competição e cooperação - e pela compreensão de que as relações de compartilhamento são uma importante habilidade empresarial.

No campo da indústria cinematográfica, esses fatos e cenários tendem a ser similares, o que nos motiva a perseguir os seguintes objetivos neste trabalho: (i) conhecer a concepção dos líderes das produtoras de cinema sobre a sua própria atividade profissional; (ii) e examinar a relevância das alianças estratégicas para produção, distribuição e consumo de uma obra cinematográfica (longa-metragem), buscando revelar as conexões e desconexões entre tais elos, que caracterizam a competitividade no setor em análise.

Tendo como referências a investigação da estrutura do setor cinematográfico nacional e as teorias de alianças estratégicas, o cinema (em especial, o elo da produção) foi compreendido sob seu aspecto mercadológico (KIRSCHBAUM, 2006; LAMPEL; SHAMSIE, 2003; MATOS; GUIMARÃES; SOUZA, 2008; MATTA; SOUZA, 2009; SHAMSIE; MARTIN; MILLER, 2009), à semelhança do que ocorre em países como Estados Unidos, França e Itália, onde a indústria mantém uma estrutura com custos fixos, orientação a metas e retenção de competências e talentos no setor. Tal postura significa que foram deixadas de lado (ou tratou-se com menor profundidade) outras abordagens, tais como os efeitos da tecnologia na estética cinematográfica (GERBASE, 2003), a discussão sobre políticas públicas para a indústria nacional (CALABRE, 2011; FORNAZARI, 2006; MINISTÉRIO DA CULTURA, 2000; REIS, 2007; SÁ NETO, 2004; XAVIER; ALMEIDA; STURM; CALIL, 2004) e os condicionantes da demanda pelo consumo de cinema e o investimento em salas de projeção no Brasil (BANCO NACIONAL DE DESENVOLVIMENTO ECONÔMICO E SOCIAL, 2000; EARP; SROULEVICH, 2008; LUCA, 2004; REIS, 2007; SLONGO; ESTEVES, 2009). 
O setor cinematográfico, criado em decorrência da aproximação da arte com a tecnologia, carrega a ambiguidade de ser uma atividade industrial - dependente de alto investimento e de retorno em longo prazo - e uma manifestação estética, cultural e artística, que acarreta no imaginário dos cidadãos uma poderosa força em termos de construção e promoção da identidade nacional (FORNAZARI, 2006). Entende-se que, a despeito da importância da indústria cinematográfica, sob o ponto de vista econômico e simbólico, a organização produtiva (modus operandi) e gerencial do setor é pouco estudada nos dias atuais. Ao realizar uma busca dos artigos ${ }^{4}$ publicados de 2010 a 2014 nas bases eletrônicas que contêm os principais periódicos da área de ciências sociais, encontramos um número limitado de trabalhos relativos à indústria cinematográfica cuja perspectiva analítica central fosse a dimensão organizacional em torno da produção audiovisual e um número ainda menor de artigos com foco na dimensão interorganizacional.

Em periódicos estrangeiros, foram localizados ${ }^{5} 43$ artigos sobre a indústria em geral. Porém, um exame detalhado mostra poucas publicações efetivamente relacionadas à organização do setor e/ou à importância das alianças estratégicas. Nesse universo, alguns trabalhos refletem, de maneira ampla, a organização do setor em contextos específicos, tais como as pesquisas de Ganti (2012), Caterer (2011), Kalemci e Ozen (2011), Nicoli (2011) e Fernandez-Blanco e Gil (2012). Esses autores analisam, respectivamente, as experiências da Índia, do Reino Unido, da Turquia, da Itália e da Espanha ${ }^{6}$. Nestes dois últimos casos, a ênfase recai sobre a influência do governo na indústria de cinema. Outros estudiosos enfatizam dimensões teóricas ligadas às alianças, tais como Parker e Cox (2013), que examinam as relações de poder nas redes globais cinematográficas, notadamente no segmento de produção de efeitos visuais; e Sorensen (2012), que examina o impacto financeiro de outsourcing e crowdsourcing nos modelos de produção de documentários.

A busca de artigos no Brasil e na América Latina7 gerou apenas 13 resultados, nenhum relacionado diretamente ao tema das alianças. Schröder (2012), por exemplo, espera compreender a organização da indústria cinematográfica brasileira, ao analisar as barreiras à entrada e a concorrência no mercado de exibição, com base em pesquisa quantitativa de abordagem econométrica. Questões tangentes às alianças foram encontradas em Ladeira (2011), que discute a convergência de setores de comunicação de massa e telecomunicações, e em Zaniratti (2010), que enfatiza os principais problemas da distribuição do cinema brasileiro e defende modelos transformadores baseados em redes sociais.

Este artigo está estruturado da seguinte forma: nesta primeira parte, a intenção é esclarecer os objetivos, o recorte e o objeto de estudo do trabalho; na segunda e terceira seções, constam, respectivamente, os levantamentos realizados sobre a estrutura da indústria cinematográfica brasileira e as bases conceituais da pesquisa; no quarto tópico, descreve-se a orientação metodológica; e, na quinta parte, está a análise dos multicasos em quatro produtoras cinematográficas, seguida das reflexões finais e dos apontamentos para pesquisas futuras.

\footnotetext{
${ }^{4}$ Para isso, foram pesquisados os principais periódicos na área de ciências sociais na base eletrônica Web of Science (Thomson Reuters), que inclui o Social Science Citation Index, e na base Scielo, de modo a contemplar a pesquisa brasileira na área.

${ }^{5}$ Para a busca dos artigos, foram utilizados os seguintes termos em inglês no campo do título: movie industry OR movie sector OR cinema industry OR cinema sector OR film industry OR film sector OR movie business OR cinema business OR film business AND alliances OR networks. ${ }^{6}$ Não é objetivo do presente artigo realizar uma análise comparada entre o modelo produtivo cinematográfico nacional e os arranjos estrangeiros. Depois de consolidarmos nosso conhecimento sobre as particularidades locais, avançaremos para a segunda etapa do projeto de pesquisa, na qual faremos estudos dessa envergadura. A pesquisa bibliográfica - nacional e internacional - feita nesse momento teve o intuito de confirmar nossa suspeita acerca da carência de investigações sobre as alianças estratégicas na indústria cinematográfica, em especial, no segmento da produção.

${ }^{7}$ Foram buscados os seguintes termos em português em todos os campos disponíveis na base Scielo: alianças OR cooperação OR colaboração OR redes OR concorrência AND cinema OR cinematográfica OR audiovisual OR salas de exibição.
} 


\section{A ORGANIZAÇÃO DA INDÚSTRIA CINEMATOGRÁFICA BRASILEIRA}

No Brasil, a indústria audiovisual é constituída de três setores interdependentes, conforme a Tabela 1.

Tabela 1 - Sistema de valor do cinema

\begin{tabular}{|c|c|c|}
\hline Grupo & Principais atividades & Principais representantes \\
\hline PRODUTOR & $\begin{array}{c}\text { concepção artística do projeto do filme; } \\
\text { filmagens e finalização do filme; } \\
\text { infraestrutura (equipamentos, escritório, estúdio } \\
\text { etc.), planejamento do filme, enquanto negócio, } \\
\text { e engenharia financeira. }\end{array}$ & $\begin{array}{c}\text { Produtoras nacionais - atuação } \\
\text { em parceria (com empresas de } \\
\text { comunicação/distribuição) ou } \\
\text { produção independente. }\end{array}$ \\
\hline DISTRIBUIDOR & $\begin{array}{r}\text { Comercialização e marketing do filme; } \\
\text { Geração e distribuição de cópias físicas. }\end{array}$ & $\begin{array}{c}\text { Majors (estúdios americanos); } \\
\text { Distribuidores independentes } \\
\text { de capital nacional (Copacaba- } \\
\text { na Filmes, Rio Filmes etc.). }\end{array}$ \\
\hline EXIBIDOR & $\begin{array}{c}\text { Investimento em infraestrutura; } \\
\text { Projeção de filmes nas diversas janelas: cinema, }\end{array}$ & $\begin{array}{c}\text { Detentores de salas de proje- } \\
\text { ção de cinema; } \\
\text { TV absinatura, locadoras, TV aberta, internet e fechada. } \\
\text { e novas mídias. }\end{array}$ \\
\hline
\end{tabular}

Fonte: Ministério da Cultura (2000).

A produção cinematográfica é constituída de empresas envolvidas na elaboração do produto audiovisual. A distribuição é dominada por estúdios americanos, conhecidos como majors, que exercem um poder quase oligopolístico, dominando o segmento de comercialização de filmes, home video e de televisão em quase todos os mercados nacionais. $O$ grupo exibidor é composto pelas janelas de exibição: salas de cinema, home video, TVs aberta e por assinatura, internet e novas mídias. Existe um déficit de cinemas no país, o que prejudica o setor produtivo, já que essa janela consiste no principal canal de escoamento da produção e na principal mídia para o filme (BANCO NACIONAL DE DESENVOLVIMENTO ECONÔMICO E SOCIAL, 2000; BAHIA, 2012).

As restrições advindas da competição no setor de distribuição e da pequena sinergia entre cinema e outras janelas, principalmente a TV aberta, constituem traços marcantes do mercado nacional e fazem dos incentivos governamentais a mola mestra do polo produtor (BAHIA, 2012; FORNAZARI, 2006). A principal fonte de financiamento da produção são as leis de incentivo fiscal (BAHIA, 2012; MATTA; SOUZA, 2009; MINISTÉRIO DA CULTURA, 2000; REIS, 2007).

De forma geral, os instrumentos de política pública (artigos 1으 e 30 da Lei do Audiovisual; Lei Rouanet; e artigo 39 da Medida Provisória 2228-1) baseiam-se na concessão de benefícios fiscais às empresas apoiadoras (AGÊNCIA NACIONAL DE CINEMA, 2005). Esse sistema de financiamento é composto pela Agência Nacional de Cinema (ANCINE) - que autoriza e acompanha os projetos audiovisuais; pela produtora, coprodutora e distribuidora - que são agentes empresariais envolvidos na pré-produção, produção e distribuição da obra audiovisual; e por empresas apoiadoras - organizações privadas dispostas a alocar recursos financeiros tendo como contrapartida benefícios fiscais (XAVIER et al., 2004).

Até 1990, o investimento direto por meio de mecanismos geridos pela estatal Embrafilme conferia ao Estado a condição de coprodutor e distribuidor dos filmes. Quando esse modelo foi extinto, gerou-se uma crise de insuficiência produtiva. O Estado reviu sua participação, entendendo que era preciso corrigir imperfeições de um mercado caracterizado por pequena escala, limitações 
tecnológicas e minguadas fontes de financiamento privado e marcado pela hegemonia da produção americana (FORNAZARI, 2006). Cria-se, assim, uma política pública de incentivo à cultura e ao cinema audiovisual, que se desloca do eixo intervencionista para o regulador. Mais tarde, em setembro de 2001, o governo cria a ANCINE, que tem por finalidade promover a regulação, a fiscalização e o fomento das atividades cinematográficas e videofonográficas (ANCINE, 2005).

Resumidamente, os mecanismos de incentivo criados a partir de meados da década de 90 consubstanciaram um modelo combinado de renúncia fiscal, participação societária nos filmes (produtores, coprodutores, distribuidores e complementors), vinculação de imagens corporativas a projetos culturais, diminuição de carga fiscal e ganhos publicitários por parte das empresas apoiadoras. Essas características permitiram a entrada de atores na indústria, com destaque para os investidores estrangeiros (coprodutores), como as majors; as empresas de comunicação, como a Globo Filmes; e as emissoras de TV a cabo (FORNAZARI, 2006).

Os esforços públicos estão, assim, excessivamente voltados à produção de filmes. Xavier et al. (2004) assinalam que o aspecto crítico é a superação do gargalo da distribuição e exibição. As condições técnicas facilitam a produção, mas ainda persiste o controle da circulação dos produtos audiovisuais por parte de grupos hegemônicos internacionais. Desse modo, a articulação entre produção, distribuição e exibição é um fator-chave do projeto audiovisual (MATTA; SOUZA, 2009; MINISTÉRIO DA CULTURA, 2000). Esse fato, ratificado por Xavier et al. (2004) e Bahia (2012), pode ser exemplificado por meio da relação distante entre a televisão e o cinema.

Diferentemente do modelo americano e europeu, desde seu nascimento no Brasil, as emissoras de televisão não compram, em proporção semelhante aos países citados, conteúdos de companhias cinematográficas ou mesmo de produtoras independentes. O financiamento das produções nacionais feitas pelas emissoras de TV ocorreu por meio da publicidade (SÁ NETO, 2004), e os conglomerados de TV aberta continuam resistindo à regulamentação da reserva de espaço para o cinema nacional.

Lampel e Shamsie (2003) elegeram duas capacitações-chaves na história da indústria americana de cinema. A primeira consiste na habilidade de mobilizar recursos (mobilizing capabilities) e diz respeito às rotinas necessárias para identificar e reunir os recursos necessários para a realização de um filme, notadamente os criativos (produtor, diretor, roteirista e elenco). A segunda, chamada de capacidades transformadoras (transforming capabilities), abrange as rotinas que orientam e monitoram os processos que utilizam tais recursos, incluindo desenvolvimento de script, iluminação/fotografia, liderança do diretor e performance dos artistas, por exemplo. Os autores relatam que a maturidade da indústria revelou que o problema central para os estúdios consiste em garantir que os recursos-chave estejam disponíveis no local e momento corretos. Projetos interrompidos em sua fase de preparação representam uma significativa perda em termos de custo de oportunidade. Assim, a habilidade de levantar os recursos para viabilizar um filme é crucial para a vantagem competitiva, o que nem sempre foi assim, já que, no primeiro estágio da indústria (até a década de 40 ), o sucesso estava predominantemente ligado ao domínio dos processos-chave de produção (desempenho operacional).

No que diz respeito à rentabilidade da atividade cinematográfica brasileira e às funções exercidas pelos agentes da indústria, os dados disponíveis são escassos, às vezes divergentes e de baixa confiabilidade. Partindo-se de Luca (2004), a Tabela 2 mostra uma distribuição das responsabilidades e dos ganhos dos envolvidos no ciclo comercial do filme (janela cinema). 
Tabela 2 - Participações na receita e responsabilidades dos agentes na cadeia cinematográfica

\begin{tabular}{|c|l|}
\hline $\begin{array}{c}\text { PRODUTOR } \\
\text { 25\% da receita líquida }\end{array}$ & É o agente que efetivamente produziu a obra e geriu esse processo. \\
\hline $\begin{array}{c}\text { DISTRIBUIDOR } \\
25 \% \text { da } \\
\text { receita líquida }\end{array}$ & $\begin{array}{l}\text { - Assume as despesas com o lançamento do filme (P\&A - Prints \& Advertising), } \\
\text { com o fornecimento e com a logística (tráfego, conservação e armazenamento) } \\
\text { de cópias para as salas de exibição e os demais gastos. } \\
\text { tamento sobre futuras receitas), que consiste em um montante referente aos } \\
\text { direitos de distribuição do filme, que é liberado antecipadamente para viabili- } \\
\text { zar a produção. }\end{array}$ \\
\hline $50 \%$ da receita líquida & Responsável pela manutenção e operação das salas de cinema. \\
\hline
\end{tabular}

Fonte: Luca (2004).

Os acordos comerciais estabelecem que as receitas iniciais com o lançamento do filme são destinadas ao reembolso das despesas incorridas pelo distribuidor. Assim, o produtor terá acesso a alguma arrecadação após o pagamento integral dessas despesas. Além desses ressarcimentos, o distribuidor cobra um percentual do faturamento pelos serviços de distribuição do filme, que varia de acordo com os riscos, os investimentos e os territórios em que a obra será veiculada (LUCA, 2004). Complementando o entendimento sobre a organização do campo, cabe destacar que:

- a dificuldade de prever o comportamento da demanda confere volatilidade ao negócio. As produtoras trabalham com uma carteira de projetos-filmes, cuja rentabilidade se apoia no subsídio cruzado entre os filmes (SHAMSIE; MARTIN; MILLER, 2009);

- a susceptibilidade ao fracasso exige uma blindagem econômica, conseguida, pela indústria americana, através de uma participação vertical na indústria, de uma produção em escala e da criação de mercados para escoar o alto volume de produção (MINISTÉRIO DA CULTURA, 2000). No Brasil, a verticalização da cadeia não aconteceu;

- devido à elevada oferta de filmes, a dependência das atividades de marketing, divulgação e distribuição (MINISTÉRIO DA CULTURA, 2000) é alta, conferindo elevado poder às majors.

Conhecer os condicionantes estruturais do segmento fílmico é fundamental para compreender os drivers da competição no setor produtivo e, dessa forma, aprofundar a investigação sobre o sentido atribuído às alianças que perpassam o filme. Sem entender o contexto, as práticas das produtoras cinematográficas ficam apartadas da realidade.

\section{ALIANÇAS EMPRESARIAIS}

Abell e Hammond (1979), em um livro clásico, publicado no final da década de 70, chamam a atenção para um aspecto, por vezes negligenciado na literatura sobre alianças estratégicas: a definição do negócio e suas implicações. Os autores advertem que a definição do negócio implica a realização de duas escolhas-chave: o escopo do negócio, em termos dos clientes atendidos (demanda), da oferta e da tecnologia; e a segmentação (diferenciação) de mercado. Portanto, a definição do negócio é o ponto de partida do planejamento estratégico, por representar uma atitude criativa, que afetará a saúde corporativa. Em função dessa interdependência, ela precede logicamente as outras decisões estratégicas - como a realização de parcerias. Sob outros termos, essa mesma concepção se manifesta no conceito de intenção ou intento estratégico, pro- 
posto por Hamel e Prahalad (1989). Os autores conferem um status especial ao estabelecimento de uma posição de liderança desejada em conjunto com critérios para o alcance dessa posição. Bethlem (2002) sugere que tal posição está associada a um dos quatro objetivos genéricos corporativos - lucro, crescimento, sobrevivência e prestígio - ou a uma combinação deles, que influenciam as escolhas empresariais.

Destarte, diferentes trajetórias tornam-se possíveis em função dos objetivos empresariais e da heterogeneidade das firmas quanto aos recursos, às rotinas, às capacidades e às competências (BARNEY, 1991; DAS; TENG, 2000; FOSS, 1997), bem como da estrutura e do ambiente regulatório do setor, como ressalta a visão porteriana sobre estratégia. Portanto, para alcançar seu intento estratégico, as empresas precisam empregar recursos e interpretar o ambiente tecnológico, institucional, cultural e social, atentando para o que deve ser mudado de forma a ajustar objetivos e metas para a obtenção de vantagens competitivas.

Nesse contexto, faz-se presente o debate sobre as alianças estratégicas como fonte redutora de anacronismos e de assimetria de informação, difusora de inovação e fomentadora de recursos para a competição. $O$ rol de abordagens que oferecem um aporte conceitual para a compreensão dos antecedentes das alianças organizacionais é extenso, e vários acadêmicos (BALESTRIN; VERSCHOORE; REYES JUNIOR, 2010; GRANDORI; SODA, 1995; OLIVERS; EBERS, 1998; VALE; LOPES, 2010) empregaram esforços para sintetizá-las. Dentre o leque de possibilidades disponíveis, optou-se, neste estudo, por entender o processo formativo das alianças pela via da Visão Baseada em Recursos (VBR). Tal escolha não significa que a compreensão da cooperação na indústria cinematográfica deve ser feita exclusivamente pelo percurso mencionado, mas tão somente deixa claro que, na visão dos autores deste trabalho, essa teoria fornece uma gama maior de explicações e insights coerentes com os múltiplos casos empíricos estudados.

\subsection{Conceito e principais antecedentes das alianças empresariais}

As alianças estratégicas são um arranjo cooperativo entre empresas, baseado na troca, no compartilhamento ou no codesenvolvimento de produtos, serviços e tecnologias (GULATI, 1998). Esses arranjos são impulsionados por motivos variados e assumem múltiplas formas, tais como joint venture; acordos de licenciamento, comercialização e distribuição; projetos de pesquisa e desenvolvimento; ações compartilhadas de marketing; consórcios; e subcontratação (HAGEDOORN; NARULA, 1996; LI; QIAN; QIAN, 2013; TSANG, 1998).

Adotando-se a tipologia de Hagedoom e Narula (1996), tais configurações podem ser categorizadas como sem participação acionária, com participação acionária e joint venture (ou união de risco, em que as parceiras criam uma empresa independente). Das e Teng (2000) possuem proposta semelhante, destacando as joint ventures; alianças com participações minoritárias; alianças baseadas em contratos bilaterais; e alianças baseadas em contratos unilaterais. As alianças unilaterais são frequentes em situações em que ocorre transferência de direitos de propriedade. Sua principal característica é a baixa necessidade de coordenação ou colaboração entre os envolvidos. Já as alianças bilaterais demandam a alocação de recursos pelos parceiros e um trabalho em conjunto realizado sistematicamente.

O exame da literatura (ALVES; PEREIRA, 2013; BALESTRIN; VERSCHOORE; REYES JUNIOR, 2010; DOZ; HAMEL, 1998; LI; QIAN; QIAN, 2013; PELLEGRIN et al., 2007; TSANG, 1998) aponta que as principais motivações e benefícios das alianças são a complementariedade de recursos em prol do aproveitamento de oportunidades de mercado e de sobrevivência (coespecialização); a necessidade de aprendizado, visando suprir déficits de habilidades; o compartilhamento de ris- 
cos e custos; a prospecção de mercados e a exploração de oportunismos; a criação de estratégias defensivas; a busca de legitimidade; o acesso a insumos; a expansão da produção; e a cooptação de rivais e complementares. Esse conjunto de aspectos contribui para a promoção da melhoria do desempenho, da competitividade, da flexibilidade gerencial (entendida como as possibilidades de reversibilidade dos compromissos assumidos) e da capacidade adaptativa das empresas, além de auxiliar o movimento de entrada/saída nos mercados.

\subsection{Alianças estratégicas sob a perspectiva da Visão Baseada em Recursos}

A VBR surge como uma abordagem alternativa à economia industrial e acredita que a vantagem competitiva depende da capacidade da organização em maximizar recursos, tendo, para tanto, de cooperar com terceiros (DAS; TENG, 2000) ${ }^{8}$. A VBR não negligencia o ambiente externo, pois entende que as empresas devem delinear contextos possíveis de atuação nos quais os diferentes recursos que possui possam ser mais produtivos (MILLER; SHAMSIE, 1996). Mais do que analisar o ambiente competitivo, as firmas devem prestar atenção em suas capacidades para explorá-las (DAS; TENG, 2000; TSANG, 1998).

Nessa perspectiva teórica, as empresas são compreendidas como uma coleção idiossincrática de capacidades e recursos heterogêneos, nem sempre transferíveis, imitáveis ou substituíveis (BARNEY, 1991; DAS; TENG, 2000; TSANG, 1998). Tsang (1998) entende que os recursos de uma empresa consistem em todos os seus ativos. Barney (1991) classifica-os como físicos (ativos físicos, localização geográfica e acesso à matéria-prima), humanos (treinamento, aprendizado, habilidades, inteligência, relacionamentos e insights de colaboradores) e organizacionais (estrutura organizacional, planejamento formal e informal, sistemas gerenciais e relacionamentos institucionais). Para Barney (1991), os recursos de uma firma geram vantagem competitiva quando são valiosos, ou seja, capazes de gerar estratégias eficientes e efetivas, são raros, difíceis de imitar e insubstituíveis.

Miller e Shamsie (1996), ao estudar os estúdios cinematográficos americanos, entre 1936 e 1965, sentiram necessidade de propor uma nova operacionalização para o conceito de recursos, dividindo-os naqueles baseados em direitos de propriedade (property-based resources) e em conhecimento (knowledge-based resources). O primeiro tipo refere-se aos recursos de difícil obtenção por terceiros (capital financeiro, físico, humano etc.), por serem assegurados legalmente através de patentes, contratos, dentre outros meios. O segundo diz respeito ao conhecimento, às habilidades e às técnicas, sendo, portanto, de difícil imitação, pois as empresas terão mais dificuldades em absorvê-los (barreiras de conhecimento). Miller e Shamsie (1996) enfatizam, ainda, um aspecto importante, por vezes esquecido: existem recursos que possuem maior grau de independência do contexto (discretos) e aqueles que são dependentes do contexto (sistemáticos). 0 valor destes últimos decorre de sua relação com um sistema ou uma rede.

Sob a ótica da VBR, é possível pensar em dois motivos genéricos para a concretização das alianças: obtenção de recursos de terceiros; e retenção e desenvolvimento dos seus recursos, a partir da combinação com os dos parceiros (DAS; TENG, 2000). Para Tsang (1998), a racionalidade por trás da criação das alianças resume-se a cinco aspectos: geração de receita; maximização da utilização de recursos; diversificação na aplicação de recursos (portfólio de recursos); imitação de recursos (capacidade absortiva); e movimento de saída do negócio, por meio da realização de joint venture ou outro tipo de acordo. Percebe-se que o elemento comum desses antecedentes é que a vantagem competitiva decorre justamente da capacidade de trocar e coordenar recursos em prol da geração de valor.

${ }_{8}$ Os autores extrapolaram o aporte teórico da VBR para o estudo do fenômeno das alianças estratégicas. 
Assim, a nosso ver, a VBR parece ser especialmente adequada para entender a formação de alianças, uma vez que, de forma geral, em um relacionamento interorganizacional sempre haverá uma contribuição recíproca de recursos para a criação de valor, estabelecendo-se uma linha sútil, em alguns casos, entre complementariedade e dependência.

\section{MÉTODOS ADOTADOS NA PESQUISA}

Estudos de caráter exploratório têm como objetivo sugerir perguntas, familiarizar-se com os fatos, descobrir categorias analíticas, apontar caminhos para investigações subsequentes e identificar problematizações (CERVO; BERVIAN; DA SILVA, 2010; MALHOTRA, 2011; YIN; GRAS$\mathrm{SI}, 2005)$. A presente pesquisa possui tal natureza, em função da lacuna de trabalhos a respeito do papel das alianças no modelo produtivo cinematográfico brasileiro e mundial. Foi utilizada a técnica de entrevista em profundidade por meio de um roteiro semiestruturado, contendo perguntas abertas que buscaram incentivar uma exposição livre e aprofundada. A estratégia de pesquisa adotada é o estudo multicasos. Tal escolha foi feita, pois é de fundamental relevância captar múltiplas visões sobre a realidade que, ao serem confrontadas, revelam um olhar mais fidedigno do fenômeno em investigação. Sob semelhante inspiração, foram coletados dados secundários sobre o setor em tela, através de sites, documentos publicados por órgãos como a ANCINE e bibliografia especializada. A investigação acerca da estrutura da indústria cinematográfica nacional, combinada com o referencial teórico, forneceu as bases conceituais para a determinação das questões orientadoras desta pesquisa, conforme mencionado na Tabela 3, exposta a seguir.

Tabela 3 - Perguntas orientadoras da pesquisa

\begin{tabular}{|c|l|}
\hline \multicolumn{2}{|c|}{ PERGUNTAS DA PESQUISA } \\
\hline $\begin{array}{c}\text { Grupo I - Relação entre o líder } \\
\text { da empresa e a definição do } \\
\text { negócio }\end{array}$ & $\begin{array}{l}\text { - Qual a concepção do gestor da empresa sobre a atividade de fazer } \\
\text { cinema e sobre o contexto empresarial em que está inserido? } \\
\text { - Qual a relação dessas percepções com a definição do negócio e, con- } \\
\text { sequentemente, com o seu posicionamento de mercado? }\end{array}$ \\
\hline $\begin{array}{c}\text { Grupo II - Formação de alian- } \\
\text { ças e geração de resultados na } \\
\text { indústria cinematográfica }\end{array}$ & $\begin{array}{l}\text { - Quais os marcos decisórios de um projeto cinematográfico? } \\
\text { - Quais os modelos de alianças, de financiamento e de retorno do pro- } \\
\text { jeto de cinema? }\end{array}$ \\
\hline
\end{tabular}

Fonte: elaborada pelos autores.

Foram ouvidas quatro produtoras cinematográficas (entrevistas realizadas com o sócio ou o gestor principal) na cidade do Rio de Janeiro: Domingos Oliveira (produtor independente), Diler \& Associados, Conspiração Filmes e Globo Filmes. As entrevistas tiveram duração aproximada de duas horas cada uma; foram gravadas, transcritas literalmente e integradas às anotações feitas in loco pelo pesquisador; e privilegiaram ora o indivíduo, ora a empresa como unidade de análise central. Após leitura minuciosa, criou-se uma ordem de agrupamento do material em função de sua relação com as perguntas orientadoras deste estudo (codificação dos dados de acordo com os grupos I e II na Tabela 3), formando um corpus rico para a análise de base interpretativa realizada apoiando-se na literatura consultada.

Os respondentes foram selecionados com base na acessibilidade, na reputação individual e na repercussão de suas empresas, formando uma amostra por conveniência. Trata-se de uma técnica não probabilística que possui limitações, como o viés de seleção; outra particularidade é que os resultados obtidos são restritos à população examinada, não permitindo generalizações e extrapolações (MALHOTRA, 2011). 


\section{ANÁLISE DOS RESULTADOS: OS MULTICASOS INVESTIGADOS}

A análise dos casos foi conduzida a partir das questões orientadoras desta pesquisa.

\subsection{Grupo I - Relação entre o líder da empresa e a definição do negócio}

Constatou-se que existem diferenças na percepção dos entrevistados sobre o que é fazer cinema. Qual a importância dessa afirmação para a abordagem gerencial assumida por esta pesquisa? A discussão infindável sobre se cinema é arte ou é indústria será, mais uma vez, inevitável, pois ela influencia significativamente importantes decisões mercadológicas. Observou-se que a concepção sobre o fazer cinematográfico cria ou desfaz restrições no ambiente de atuação dos entrevistados. Tais restrições influenciam diretamente a definição do negócio e das alianças para executar um projeto, evidenciando um paralelismo teórico com Abell e Hammond (1979). Em um extremo, tem-se Domingos Oliveira, que defende a ideia de que cinema é arte. Em outro, encontra-se a Diler \& Associados, defensora do cinema como indústria. As citações a seguir exemplificam essa dicotomia:

É miopia achar que arte é apenas entretenimento e diversão. Essa é uma de suas facetas. Arte funciona como um regulador social, ela dignifica o homem, educa, transmite valores (Domingos Oliveira).

Nós desenvolvemos um processo próprio, porque nos posicionamos como indústria. Existem vários posicionamentos de uma produção cinematográfica. [...] O que é visão artística cinematográfica? É você... como um quadro ou uma poesia ou como um livro, você é inspirado por algum motivo, por alguma ideia e você desenvolve e realiza sem nenhum compromisso externo, sem observação da realidade ou sem dimensionamento da perspectiva de retorno. Você vai para o mercado vender e pode ou não vender [produtivismo]. [...] A era do produtivismo foi substituída pela era do marketing. O que é o marketing em essência? Ao invés de você produzir e ir ao mercado vender, você vai primeiro ao mercado e ouve o mercado, observa a realidade e vê quais são os problemas e encontra as oportunidades (Diler \& Associados).

Globo Filmes e Conspiração Filmes possuem, por sua vez, uma visão que mistura os elementos supracitados. No que diz respeito à Globo Filmes, dois balizadores definem o seu modelo de atuação:

Balizador 1: valorizar e fortalecer o conteúdo audiovisual nacional. [...] Então tem um posicionamento político e estratégico importante nisto;

Balizador 2: formar público - assim, o segundo grande objetivo estratégico é como a gente entraria nesse mercado, como a gente contribuiria para formar público, para aumentar o número de espectadores de filmes nacionais? (Globo Filmes).

Essa empresa pertence ao maior grupo de comunicação do país. Portanto, é inegável que este aspecto exerce influência no seu posicionamento:

[...] a televisão para sobreviver [...] depende diretamente da audiência. Mas o que é a audiência? É você saber interpretar, por pesquisas, por metodologia, o que a população gosta. [...] Então está no sangue das pessoas da televisão essa sensibilidade com o telespectador. O que acontece na minha avaliação no cinema, principalmente do Cinema Novo para cá - não sou um especialista nisto... o Cinema Novo [...] não era um cinema popular e aí como modelo de negócio, é um modelo terrível [...] (Globo Filmes).

Já a Conspiração Filmes tem outra percepção, baseada em um viés artístico forte. Seus 
sócios são, em grande parte, diretores de filmes publicitários e documentários, e, em todo projeto, um deles assume a função de liderança. Esse aspecto a diferencia da Diler \& Associados. Porém, o que a distingue do Domingos Oliveira é que suas produções são voltadas para o grande público. Pode-se dizer que a Conspiração Filmes tenta unir liberdade de criação (capital simbólico) e orientação ao mercado (capital financeiro). Assim, conforme aponta Bethlem (2002), as organizações almejam, além do sucesso financeiro, prestígio (Conspiração Filmes), crescimento (Diler \& Associados), sobrevivência (Domingos Oliveira) e/ou prestígio e crescimento (Globo Filmes).

\subsection{Grupo II - Formação de alianças e geração de resultados na indústria cinematográfica}

Este tópico pretende esclarecer aspectos sobre os marcos decisórios de um projeto cinematográfico, bem como lançar luz sobre a natureza das relações entre as produtoras investigadas. Lampel e Shamsie (2003) e Shamsie, Martin e Miller (2009) afirmam que a atividade cinematográfica é um empreendimento baseado em projeto. Empiricamente, constatou-se que o ciclo de vida de um longa-metragem possui três fases ligadas ao elo produtor: seleção, planejamento e execução. A primeira delas é a escolha do roteiro. A segunda pode ser compreendida como a determinação do design do projeto, na qual a principal tarefa realizada é a captação de recursos. Já a última fase é a realização das filmagens. Nesse momento, são estabelecidas alianças com fornecedores de equipamentos, distribuidores e, em menor grau, exibidores. Portanto, a formação de alianças com ou sem participação acionária - utilizando a terminologia de Hagedoom e Narula (1996) - surge no nascimento do filme, desde a etapa de seleção, conforme apontado por Matta e Souza (2009).

Tradicionalmente, sabe-se que as majors são um importante parceiro no projeto cinematográfico. A Conspiração Filmes revelou que, além de sua contribuição financeira, as majors usam sua expertise para avaliar a viabilidade comercial de um filme.

Matta e Souza (2009) também observaram que as majors selecionam a oferta de filmes, exigindo dos produtores mais atenção na seleção dos projetos. Fica evidente que as majors fornecem recursos financeiros e conhecimento artístico-mercadológico, enquanto que as produtoras proveem os conhecimentos sobre a realização audiovisual.

Outro aspecto a ser ressaltado é a participação da Globo Filmes, que apoia um projeto de duas maneiras, pelo menos: oferta de mídia e consultoria artística (semelhante às majors); e, eventualmente, cedendo atores do seu casting. $\mathrm{O}$ acesso ao casting da TV Globo é uma rica possibilidade para a produtora parceira, devido à representatividade do capital artístico do grupo Globo junto à população. Por se tratar de um recurso protegido legalmente por contrato - property-based resource, na tipologia de Miller e Shamsie (1996) -, sem uma aliança esse tipo de recurso seria inacessível. Através do que se convencionou chamar, neste artigo, de consultoria oferecida pelo grupo Globo, ocorre uma transferência de conhecimentos (knowledge-based resource) mercadológicos e artísticos que auxiliam a concepção, a execução e a distribuição da obra cinematográfica.

A Diler \& Associados trouxe um elemento novo ao revelar que a produtora recorre a um agente financiador externo, ou seja, a um investidor de risco, que decide aportar recursos e se tornar cotista. Nem todas as produtoras conseguem a participação desse agente, pois ele se une ao filme por razões financeiras. Contudo, a identificação desse investidor pessoa física está atrelada ao capital social detido pela produtora.

Diante desse cenário, surge uma importante reflexão: qual a lógica de criação de valor das alianças realizadas? Flexibilidade, iniciativa empreendedora e capacidade de análise do mercado parecem guiar a formação de parcerias na Diler \& Associados. Em Domingos Oliveira, flexibilidade e iniciativa devem ser ressaltadas, mas a percepção é de que a coespecialização 
consiste no principal imperativo para as alianças. Neste caso, recursos escassos e habilidades são combinados com a expectativa de explorar o mercado independente. A Conspiração Filmes, por sua vez, possui tendência à coespecialização, com destaque para o relacionamento com a Globo Filmes e com a major. Por fim, a Globo Filmes estabelece suas alianças praticamente por meio da cooptação, tendo em vista sua visível superioridade, frente às produtoras brasileiras de cinema.

No que diz respeito ao modelo de financiamento do setor, pelo que foi apurado, a estrutura padrão é composta de produtor-coprodutor-empresa privada (via artigo 1ㅇ da Lei do Audiovisual); distribuidor (via artigo 3o da Lei do Audiovisual); e investidor de risco (recurso próprio) - merchandising (empresa privada). Com exceção do último, todos, em geral, tornam-se cotistas do filme. Podem participar do arranjo a Globo Filmes, os fornecedores de infraestrutura (iluminação, equipamentos de filmagens etc.), as produtoras complementares (edição, finalização etc.) e os talentos do filme (atores, diretores, produtores, roteirista e autor da ideia). Dependendo do projeto, todos podem ser cotistas. A Tabela 4, a seguir, revela o quadro societário de um filme, com base nas informações obtidas da Diler \& Associados.

Tabela 4 - Quadro societário de um projeto cinematográfico

\begin{tabular}{|c|c|}
\hline Sócios do filme & Percentual da cota \\
\hline Major - artigo 3o & 40\% (variação: 30\% a 40\%) \\
\hline Globo Filmes & $15 \%$ (variação: 15\% a 20\%) \\
\hline Talentos - roteirista, diretor, elenco & $12 \%$ \\
\hline Infraestrutura e parceiros complementares & $3 \%$ \\
\hline Investidor de risco & $3 \%$ (variação: 3 a 10) \\
\hline Coprodutoras - artigo 10 & $10 \%$ \\
\hline Diler \& Associados & $12 \%$ \\
\hline
\end{tabular}

Fonte: pesquisa de campo.

Conhecer o pacto comercial que rege as relações entre os players é um aspecto seminal para o exame da fonte de valor das produtoras. As entrevistas confirmam, em grande parte, as informações fornecidas por Luca (2004), conforme pode ser visto nas constatações a seguir:

- 1a constatação - a partir do momento em que o filme gera receita com a bilheteria, o distribuidor ganha a sua porcentagem (relativa à distribuição) e, simultaneamente, até que o P\&A (print \& adversiting) seja quitado, o percentual que cabe ao produtor pagar;

- 2 a constatação - os gastos com P\&A são pagos, em um primeiro instante, pelo distribuidor. $O$ produtor herda essa dívida, que não precisa ser paga caso o filme fracasse. Nas demais janelas, a responsabilidade da dívida ainda permanece;

- 3a constatação - a Globo Filmes possui um modelo misto, em função de sua atuação como distribuidora e produtora. A empresa é sócia dos filmes que apoia e concomitantemente recebe um percentual da distribuição.

No que diz respeito aos percentuais de remuneração na cadeia, houve variações entre os participantes da pesquisa. A Tabela 5 ilustra o que foi informado por cada entrevistado. 
Tabela 5 - Distribuição da receita bruta das salas de cinema (Brasil)

\begin{tabular}{|c|c|c|c|}
\hline & Conspiração & Diler \& Associados & Globo Filmes \\
\hline Exibidor & $50 \%$ & $52 \%$ & $50 \%$ \\
\hline Distribuidor & $7,5-15 \%$ & $15-30 \%$ & $20-30 \%$ \\
\hline Produtor & $35-42,5 \%$ & $18-33 \%$ & $20-30 \%$ \\
\hline
\end{tabular}

Fonte: pesquisa de campo.

Nota: a referência para o cálculo das porcentagens é a renda bruta de bilheteria; o papel de distribuidor e do produtor pode ser exercido por uma ou mais empresas.

A diferença maior ocorre entre a Conspiração Filmes, de um lado, e a Globo Filmes e a Diler \& Associados, de outro. Parte dela pode ser explicada pelo fato de as negociações variarem em cada produtora e em cada projeto - dependendo do orçamento do filme e do envolvimento com parceiros, sugerindo que não há um modelo rígido de remuneração. Nas demais janelas de exibição (TV e home video), são praticados outros percentuais, conforme aponta a Tabela 6.

Tabela 6 - Distribuição da receita líquida de um filme entre as janelas de exibição

\begin{tabular}{|c|c|c|c|}
\hline & $\begin{array}{c}\text { Conspiração Fil- } \\
\text { mes }\end{array}$ & $\begin{array}{c}\text { Diler \& Associa- } \\
\text { dos }\end{array}$ & Globo Filmes \\
\hline Salas de cinema & $64 \%$ & $52,5 \%$ & $60 \%$ \\
\hline Home video (varejo e locadoras) & $20 \%$ & $30,3 \%$ & $20 \%$ \\
\hline TV - aberta e fechada & $16 \%$ & $17,2 \%$ & $20 \%$ \\
\hline
\end{tabular}

Fonte: pesquisa de campo.

Nota: receita líquida $=$ receita bruta - impostos - gastos com comercialização (P\&A e outros).

Os números indicam um consenso sobre a superioridade da janela cinema. A maior disparidade está no percentual da Diler \& Associados no segmento home video, talvez pelo posicionamento de mercado e/ou pelo perfil da sua carteira de filmes.

\subsection{Paralelismo com os principais conceitos teóricos propostos no trabalho}

O quadro retratado indica a fragilidade do setor produtivo cinematográfico diante da matriz televisa e a dependência dos recursos governamentais, aspectos que implicam uma cascata de dependências, a começar das empresas que aportam recursos nos filmes via leis de incentivo, passando pelo distribuidor, que contribui com dinheiro (também via lei de incentivo) e conhecimento, e terminando na Globo Filmes, que disponibiliza sua estrutura produtiva, sua expertise mercadológico, seu star system e seu potencial midiático.

As produtoras necessitam de recursos financeiros, de consultoria artística, de acesso ao consumidor e a canais internacionais de distribuição e também de legitimidade perante os potenciais patrocinadores do filme. Caso obtenham o apoio da Globo Filmes e/ou da major, conseguem também a legitimidade que precisam para acelerar a captação de recursos. Por sua vez, as distribuidoras têm interesse que surjam projetos nacionais com potencial de sucesso, afinal, no negócio em que estão, é crucial trabalhar com uma carteira de filmes que tenham apelo junto ao público. E, ainda que exista uma dominação de películas norte-americanas, há espaço para as iniciativas nacionais. A Globo Filmes, de igual modo, atenta ao avanço do conteúdo estrangeiro no Brasil e do conteúdo nacional gerado por meio de parcerias entre as majors e produtoras locais, preocupando-se em consolidar sua posição no cinema brasileiro para não perder o posto de 
empresa líder no provimento de conteúdo em diversas plataformas. Essa complexa socialidade permite a seguinte leitura: as alianças surgem como um movimento necessário para o funcionamento global da cadeia, mas também há uma forte relação de dependência das produtoras com relação aos demais elos, em função da assimetria de poder na indústria. Complementariedade e dependência andam, assim, pari passu.

A Tabela 4 mostrou como o quadro societário do filme é constituído de múltiplos atores, cada qual com suas atividades. Uma hipótese exploratória lançada por este estudo é de que as alianças sejam uma resposta dos realizadores fílmicos para minimizar os esforços necessários para combinar uma multiplicidade de especialidades e produzir um filme. As parcerias seriam, nesse sentido, um meio de aumentar a eficiência das trocas. A incorporação dos talentos, dos complementors (fornecedores de iluminação, equipamentos de filmagens etc.), das majors e da Globo Filmes, por exemplo, no quadro societário do filme, ao mesmo tempo, em que constitui um reflexo das características estruturais e legais do setor, indica a necessidade de dividir responsabilidades e de aumentar o senso de comprometimento com o projeto.

Diante do que foi investigado, conclui-se que as principais motivações das alianças são a complementariedade de recursos. Como benefícios, destacam-se a possibilidade de aproveitar as oportunidades de mercado moldadas pela configuração da indústria (relação recurso-contexto); o compartilhamento de riscos; a criação de estratégias defensivas frente à concorrência; a busca de legitimidade; o acesso a recursos financeiros, artísticos e de conhecimentos sobre a viabilidade financeira e mercadológica de um projeto; e a cooptação de firmas complementares. Como contraponto, ressalta-se uma forte dependência de recursos, fruto da assimetria de poder criada e reproduzida pela estrutura da indústria.

Cabe tecer comentários finais à luz do trabalho de Lampel e Shamsie (2003). Esses autores afirmam que, no contexto estadunidense, a participação dos recursos criativos no filme determina, significativamente, seu desempenho. Kirschbaum (2006) encontrou, no cinema brasileiro, situação diferente ao perceber que os recursos de transformação são um previsor melhor da popularidade do filme.

As evidências encontradas apontam para uma concordância com Kirschbaum, embora seja necessário acrescentar que o sucesso na indústria está relacionado também à visão do empreendedor sobre o seu próprio negócio - ou seja, à importância simbólica do fazer cinematográfico - e, no caso do cinema comercial, à sua capacidade de realizar alianças verticais, especialmente com o distribuidor e com a Globo Filmes. Ambos contribuem na transformação de recursos diretamente necessários ao filme (como, por exemplo, na seleção dos projetos, na escolha do elenco e da equipe e na condução artística das filmagens) e indiretamente necessários (divulgação e legitimação da película). Esse nível acentuado de dependência é uma decorrência da estrutura da indústria, sendo, portanto, uma especificidade do contexto nacional. Assim, a articulação com ambos os atores é um recurso sistemático (MILLER; SHAMSIE, 1996) para as produtoras de cinema. Naturalmente, tais colocações não podem ser tomadas como padrão da indústria, em função do desenho metodológico do presente estudo.

\section{REFLEXÕES FINAIS}

O esforço dedicado à compreensão da estrutura da indústria cinematográfica brasileira, associado às entrevistas com produtores fílmicos, suscitou formulações relevantes - sob a luz da população examinada - a respeito da competitividade no setor e do papel desempenhado pelas alianças nesse contexto. A primeira delas é que parece sensato afirmar que a visão sobre o fazer 
cinematográfico é um dos aspectos que influencia o posicionamento de mercado das produtoras e os arranjos formados. A afirmação de que, em tempos atuais, há uma tendência, em variados setores, à extrapolação dos limites da firma (BARNEY, 1991; DAS; TENG, 2000; DOZ; HAMEL, 1998; PELLEGRIN et al., 2007) parece verdadeira no campo cinematográfico.

A indústria americana fez esse movimento em direção a uma hierarquia em rede no ano de 1920 (LAMPEL; SHAMSIE, 2003). No Brasil, esta transição foi intensificada com as alterações no marco legal do setor. O Estado abandonou o modelo de investimento direto na produção, via a Embrafilme, e estabeleceu incentivos indiretos, que obrigaram a articulação dos produtores com empresas patrocinadoras e outros agentes do campo. Nesse novo modelo, como pôde ser visto nos casos examinados neste estudo, a participação do distribuidor cresceu em importância. Além das funções de distribuição e divulgação do filme (tradicionalmente exercidas na indústria), esses players atuam na seleção dos projetos a serem executados e no financiamento da produção, retendo parte significativa do lucro na indústria (profit share). Os produtores, orientados para um cinema comercial, como Conspiração Filmes e Diler \& Associados, enxergam tal participação como vital, pois o distribuidor aumenta o potencial de sucesso de seus empreendimentos. A crítica frequentemente apresentada a esse arranjo é que apenas projetos com apelo comercial (o que não necessariamente quer dizer que os mesmos tenham qualidade ruim) chegarão às biIheterias. Ou seja, a iniciativa privada é que seleciona o que será visto pela população brasileira, mas quem financia a indústria é o Estado.

Em função do domínio oligopolista das majors, o setor nacional herdou o padrão americano de divisão de receitas. Entretanto, a estrutura mercadológica dos Estados Unidos é baseada no modelo de integração vertical (os estúdios são de propriedade das majors) e em uma relação estreita com as emissoras de televisão, em função de leis antigas que obrigam a veiculação de conteúdos independentes nas emissoras. Outras diferenças significativas consistem no tamanho do seu mercado consumidor, na preferência nacional do norte-americano pelo cinema e na relação histórica do mesmo com o fortalecimento do nacionalismo e da internacionalização de seu país. Esses fatos, somados à diminuição do ciclo de vida do produto filme e ao pequeno percentual de projetos que conseguem captar recursos junto à iniciativa privada (por meio dos mecanismos já citados), assevera a competitividade na produção.

Outros aspectos, sob a ótica da demanda, não analisados neste artigo, também precisam ser levados em consideração no exame da competitividade da indústria, tais como: o alto preço dos ingressos (no Brasil, o peso relativo do ingresso em relação à renda é maior do que nos Estados Unidos); o elevado custo total da ida ao cinema; a existência de substitutos (entretenimento doméstico, lan games, TV paga etc.); o barateamento de aparelhos eletrônicos e o aumento da oferta de crédito para consumo desses bens; a pirataria elevada; e a diminuição da janela cinema, que foi cedendo espaço para a TV paga e para o home video (EARP; SROULEVICH, 2008; REIS, 2007).

Conclui-se o trabalho na expectativa de que o exame aprofundado das produtoras e de suas relações com os demais elos envolvidos na produção cinematográfica tenha proporcionado uma compreensão sensível do setor em estudo e descortinado possibilidades de pesquisa. Sugere-se, assim, para estudos futuros, o aprofundamento do debate sobre a relação entre o significado do fazer cinematográfico e as alianças estratégicas dos empreendedores. As pesquisas de Bendassolli e Wood Jr. (2010) e Bendassolli e Borges-Andrade (2011) representam um ponto de partida seguro nessa direção. De igual modo, acredita-se que o emprego das bases teóricas da sociologia econômica (GRANOVETTER, 2007; GULATI, 1998), instrumentalizadas por meio da técnica de análise de redes sociais (ARS), promoverá um melhor entendimento do comportamento dos envolvidos na cadeia produtiva do cinema. Apropriando-se da vertente onto-epistemológica 
da estratégia como prática social (EPS), seria rico um estudo que se concentrasse no mapeamento das microatividades de um filme, como fizeram Saraiva et al. (2011) ao estudarem as práticas do Grupo Corpo, uma equipe de dança. A observação dos mecanismos contratuais e de coordenação existentes nos arranjos estabelecidos também é um promissor nicho de pesquisa (cf. CAVES, 2003; BATISTA et al., 2011).

Por fim, sugere-se a investigação da percepção e do comportamento dos realizadores fílmicos em relação às oportunidades e aos desafios gerados pelas tecnologias emergentes que perpassam o setor, lançando mão do conceito de experimentação seletiva (visão periférica para identificar oportunidades e ameaças não visíveis através do foco único das empresas) de Day e Shoemaker (2004).

\section{REFERÊNCIAS}

ABELL, D.; HAMMOND, J. Defining the business and making the bridge to other strategic decisions. Strategic market planning: problems and analytical approaches. Englewood Cliffs: Prentice Hall, p. 389-407, 1979.

ALVES, J. N.; PEREIRA, B. A. D. Análise das publicações nacionais sobre estudos em relacionamentos interorganizacionais 20042009. Revista de Administração e Inovação, v. 10, n. 2, p. 169-198, 2013.

AGÊNCIA NACIONAL DO CINEMA. Manual do Produtor. Cinema \& audiovisual. Rio de Janeiro: ANCINE, 2005.

BAHIA, L. Discursos, políticas e ações: processos de industrialização do campo cinematográfico brasileiro. São Paulo: Itaú Cultural/lluminuras, 2012.

BALESTRIN, A.; VERSCHOORE, J. Redes de cooperação empresarial: estratégias de gestão na nova economia. Porto Alegre: Bookman, 2008.

BALESTRIN, A.; VERSCHOORE, J. R.; REYES JUNIOR, E. O campo de estudo sobre redes de cooperação interorganizacional no Brasil. Revista de Administração Contemporânea, v. 14, n. 3, p. 458-477, 2010.

BANCO NACIONAL DE DESENVOLVIMENTO ECONÔMICO E SOCIAL. Panorama atual do mercado de salas de exibição no Brasil. Rio de Janeiro: BNDES/Setorial 12, 2000.
BARNEY, J. Firm resources and sustained competitive advantage. Journal of management, v. 17, n. 1, p. 99-120, 1991.

BATISTA, P. C. S. et al. As relações contratuais das indústrias criativas: o caso dos quadrinhos no Ceará. Cadernos EBAPE.BR, v. 9, n. 2, p. 377-393, 2011.

BENDASSOLLI, P.; BORGES-ANDRADE, J. E. Significado do trabalho nas indústrias criativas. Revista de Administração de Empresas, v. 51, n. 2, p. 143-159, 2011.

BENDASSOLLI,P.;WOODJR., T.Oparadoxode Mozart: carreiras nas indústrias criativas. Organizações \& Sociedade, v. 17, n. 53, p. 259-277, 2010.

BETHLEM, A. D. S. Estratégia empresarial: conceitos, processo e administração estratégica. São Paulo: Atlas, 2002.

CALABRE, L. Políticas culturais: teoria e práxis. São Paulo: Itaú Cultural; Rio de Janeiro: Fundação Casa de Rui Barbosa, 2011.

CATERER, J. Reinventing the British film industry: the Group Production Plan and the National Lottery Franchise Scheme. International Journal of Cultural Policy, v. 17, n. 1, p. 94-105, 2011.

CAVES, R. E. Contracts between art and commerce. The Journal of Economic Perspectives, v. 17, n. 2, p. 73-84, 2003.

CERVO, A. L.; BERVIAN, P. A.; DA SILVA, R. Metodologia científica. São Paulo: Pearson Prentice Hall, 2010. 
DAS, T. K.; TENG, B. S. A resource-based theory of strategic alliances. Journal of management, v. 16, n.1, p. 31-61, 2000.

DAY, G. S.; SCHOEMAKER, P. Peripheral vision: sensing and acting on weak signals. Long Range Planning, v. 37, n. 2, p. 117-121, 2004.

DOZ, Y. L.; HAMEL, G. Alliance Advantage The Art of Creating Value Through Partnering. Boston, MA: Harvard Business School Press, 1998.

EARP, F; SROULEVICH, H. O mercado de cinema no Brasil. In EARP, F.; SROULEVICH, H.; SOUZA, R. G. Dois estudos sobre economia do cinema no Brasil. TD 0002/2008. (Série Textos para Discussão), 2008.

FERNANDEZ-BLANCO, V.; GIL, R. Underneath the Red Carpet: Government Intervention in the Spanish Movie Industry. Journal of Media Economics, v. 25, n. 1, p. 54-72, 2012.

FORNAZARI, F. K. Instituições do Estado e políticas de regulação e incentivo ao cinema no Brasil: o caso Ancine e Ancinav. RAP, v. 40, n. 4, p. 647-77, 2006.

FOSS, N. J. (Ed.). Resources, Firms, and Stratregies: A Reader in the Resource-based Perspective. Oxford: Oxford University Press, 1997.

GANTI, T. Producing Bollywood: Inside the Contemporary Hindi Film Industry. Duke University Press, 2012.

GERBASE, C. Impacto das tecnologias digitais na narrativa cinematográfica. 2003. Tese (Doutorado em Comunicação Social) Faculdade de Comunicação Social, Pontifícia Universidade Católica do Rio Grande Do Sul, Porto Alegre, RS, Brasil, 2003.

GRANDORI, A.; SODA, G. Inter-firm networks: antecedents, mechanisms and forms. Organization studies, v. 16, n. 2, p. 183214, 1995.
GRANOVETTER, M. Ação econômica e estrutura social: o problema da imersão. RAE-eletrônica, v. 6, n. 1, 2007.

GULATI, R. Alliances and networks. Strategic management journal, v. 19, n. 4, p. 293-317, 1998.

HAGEDOORN, J.; NARULA, R. Choosing organizational modes of strategic technology partnering: international and sectoral differences. Journal of international business studies, p. 265-284, 1996.

HAMEL, G.; PRAHALAD, C. K. Strategic Intent. Harvard Business Review, p. 63-76, 1989.

KALEMCI, R. A.; OZEN, S. Institutional Change in the Turkish Film Industry (1950-2006): Social Exclusion Impact of Globalization. Amme Idaresi Dergisi, v. 44, n. 1, p. 51-88, 2011.

KIRSCHBAUM, C. Renascença da indústria brasileira de filmes: destinos entrelaçados? Revista de Administração de Empresas, v. 46, n. 3, p. 58-71, 2006.

LADEIRA, J. M. A convergência recente entre os setores brasileiros de comunicação de massa e de telecomunicações. Intercom: Revista Brasileira de Ciências da Comunicação, v. 34, n. 2, p. 219-235, 2011

LAMPEL, J.; SHAMSIE, J. Capabilities in Motion: New Organizational Forms and the Reshaping of the Hollywood Movie Industry. Journal of Management Studies, v. 40, n. 8, p. 21892210, 2003.

LI, L.; QIAN, G.; QIAN, Z. Do partners in international strategic alliances share resources, costs, and risks? Journal of Business Research, v. 66, n. 4, p. 489-498, 2013.

LUCA, L. G. A. Cinema digital: um novo cinema? São Paulo: Impressa Oficial - Fundacão Padre Anchieta, 2004.

MALHOTRA, N. K. Pesquisa de marketing: foco na decisão. São Paulo: Pearson Prentice Hall, 2011. 
MATOS, M. G. P. D.; GUIMARÃES, V.; SOUZA, R. G. E. O sistema produtivo e inovativo local de audiovisual do Rio de Janeiro. Nota Técnica, $v$. 10, n. 08, 2008.

MATTA, J. P. R.; SOUZA, E. R. L. C. Cidade de Deus e Janela da Alma: um estudo sobre a cadeia produtiva do cinema brasileiro. Revista de Administração de Empresas, v. 49, n. 1, p. 27-37, 2009.

MILLER, D.; SHAMSIE, J. The resourcebased view of the firm in two environments: The Hollywood film studios from 1936 to 1965. Academy of management journal, v. 39, n. 3, p. 519-543, 1996.

MINISTÉRIO DA CULTURA. Secretaria do Audiovisual. Diagnóstico governamental da cadeia produtiva do audiovisual. 2000. Disponível em: <http://www.minc.gov.br/ relats/relats.htm>. Acesso em: 20/07/2005.

NICOLI, M. Entrepreneurs and the State in the Italian Film Industry, 1919-1935. Business History Review, v. 85, n. 4, p. 775-798, 2011.

OLIVER, A. L.; EBERS, M. Networking network studies: an analysis of conceptual configurations in the study of interorganizational relationships. Organization Studies, v. 19, n. 4, p. 549-583, 1998.

PARKER, R.; COX, S. Power Relations and Small and Medium- sized Enterprise Strategies for Capturing Value in Global Production Networks: Visual Effects (VFX) Service Firms in the Hollywood Film Industry. Regional Studies, v. 47, n. 7, p. 1095-1110, 2013.

PELLEGRIN, I. et al. Redes de inovação: construção e gestão da cooperação próinovação. Revista de Administração da Universidade de São Paulo, v. 42, n. 3, 2007.

REIS, A. C. F. Economia da cultura e desenvolvimento sustentável: o caleidoscópio da cultura. São Paulo: Editora Manole, 2007.

SÁ NETO, A. A. F. O pensamento industrial cinematográfico brasileiro. 2004. $284 \mathrm{f}$. Tese (Doutorado em Comunicação, Multimeios) Instituto de Artes, Universidade Estadual de Campinas, Campinas, 2004.

SARAIVA, E. V. et al. Um "Pas de Deux" da estratégia com a arte: as práticas do Grupo Corpo de Balé. Revista de Administração Contemporânea, v. 15, n. 6, p. 1016-1039, 2011.

SCHRÖDER, B. Práticas restritivas, barreiras à entrada e concorrência no mercado brasileiro de exibição cinematográfica. Revista Brasileira de Economia, v. 66, n. 1, p. 49-77, 2012.

SHAMSIE, J.; MARTIN, X.; MILLER, D. In with the old, in with the new: Capabilities, strategies, and performance among the Hollywood studios. Strategic Management Journal, v. 30, n. 13, p. 1440-1452, 2009.

SLONGO, L. A.; ESTEVES, P. S. O filme ou a sala? $O$ que leva o espectador porto-alegrense ao cinema? Revista de Gestão, v. 16, n. 4, p. 7792, 2009.

SORENSEN, I. E. Crowdsourcing and outsourcing: the impact of online funding and distribution on the documentary film industry in the UK. Media Culture \& Society, v. 34, n. 6, p. 726-743, 2012.

TSANG, E. W. Motives for strategic alliance: a resource-based perspective. Scandinavian Journal of Management, v. 14, n. 3, p. 207221, 1998.

VALE, G. M. V.; LOPES, H. E. G. Cooperação e alianças: perspectivas teóricas e suas articulações no contexto do pensamento estratégico. Revista de Administração Contemporânea, v. 14, n. 4, p. 722-737, 2010.

XAVIER, I. et al. Limites do controle: A proposta de regulação do setor audiovisual brasileiro. Novos Estudos Cebrap, v. 70, p. 115139, 2004.

YIN, R. K.; GRASSI, D. Estudo de caso: 
planejamento e método. Porto Alegre:

Bookman, 2005.

ZANIRATTI, C. P. Informação, fluxos e filmes: as redes sociais e a distribuição do Cinema Brasileiro. Perspectivas em Ciência da Informação, v, 15, n. 1, p. 329-329, 2010. 